\title{
ONREL
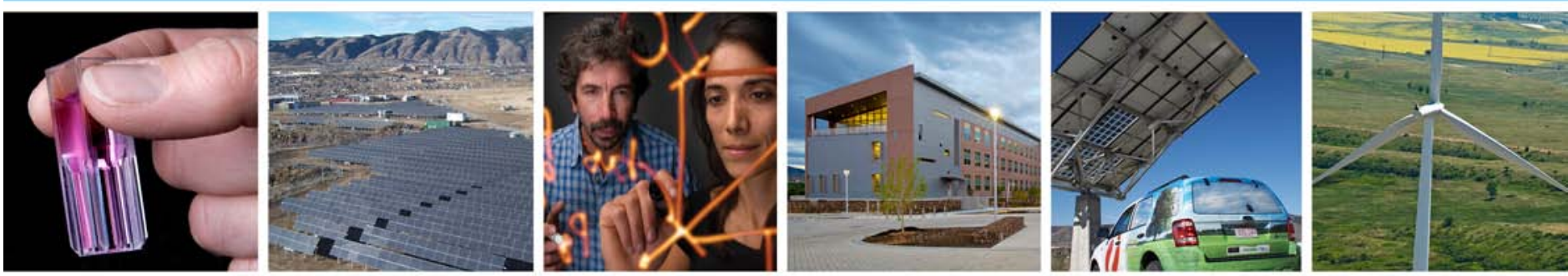

\section{Marine Hydrokinetic Turbine Power-Take-Off Design for Optimal Performance and Low Impact on Cost-of-Energy}

\section{Preprint}

M. Beam, B. Kline, B. Elbing, W. Straka, and A. Fontaine Penn State University

M. Lawson, Y. Li, and R. Thresher National Renewable Energy Laboratory

M. Previsic

Re VisionConsulting, LLC

To be presented at the $31^{\text {st }}$ International Conference on Ocean Offshore and Arctic Engineering (OMAE)

Rio de Janeiro, Brazil

June 10-15, 2012

NREL is a national laboratory of the U.S. Department of Energy, Office of Energy Efficiency \& Renewable Energy, operated by the Alliance for Sustainable Energy, LLC.

Conference Paper

NREL/CP-5000-54410

April 2012

Contract No. DE-AC36-08G028308 


\section{NOTICE}

The submitted manuscript has been offered by an employee of the Alliance for Sustainable Energy, LLC (Alliance), a contractor of the US Government under Contract No. DE-AC36-08GO28308. Accordingly, the US Government and Alliance retain a nonexclusive royalty-free license to publish or reproduce the published form of this contribution, or allow others to do so, for US Government purposes.

This report was prepared as an account of work sponsored by an agency of the United States government. Neither the United States government nor any agency thereof, nor any of their employees, makes any warranty, express or implied, or assumes any legal liability or responsibility for the accuracy, completeness, or usefulness of any information, apparatus, product, or process disclosed, or represents that its use would not infringe privately owned rights. Reference herein to any specific commercial product, process, or service by trade name, trademark, manufacturer, or otherwise does not necessarily constitute or imply its endorsement, recommendation, or favoring by the United States government or any agency thereof. The views and opinions of authors expressed herein do not necessarily state or reflect those of the United States government or any agency thereof.

Available electronically at http://www.osti.gov/bridge

Available for a processing fee to U.S. Department of Energy and its contractors, in paper, from:

U.S. Department of Energy

Office of Scientific and Technical Information

P.O. Box 62

Oak Ridge, TN 37831-0062

phone: 865.576 .8401

fax: 865.576 .5728

email: mailto:reports@adonis.osti.gov

Available for sale to the public, in paper, from:

U.S. Department of Commerce

National Technical Information Service

5285 Port Royal Road

Springfield, VA 22161

phone: 800.553 .6847

fax: 703.605.6900

email: orders@ntis.fedworld.gov

online ordering: http://www.ntis.gov/help/ordermethods.aspx

Cover Photos: (left to right) PIX 16416, PIX 17423, PIX 16560, PIX 17613, PIX 17436, PIX 17721

Printed on paper containing at least $50 \%$ wastepaper, including $10 \%$ post consumer waste. 


\section{Marine Hydrokinetic Turbine Power-Take-Off Design for Optimal Performance and Low Impact on Cost-of-Energy}

\author{
Mike J. Beam \\ Applied Research Lab / Penn \\ State University \\ PO Box 30, State College, PA, \\ 16804-0030 \\ William Straka \\ ARL / PSU \\ State College, PA, 16804-0030
}

Ye Li

Nat. Renewable Energy Lab

Golden, CO 80401-3393

\author{
Brian I. Kline \\ Applied Research Lab / Penn \\ State University \\ PO Box 30, State College, PA, \\ 16804-0030 \\ Arnold A. Fontaine \\ ARL / PSU \\ State College, PA, 16804-0030
}

\section{Robert Thresher}

Nat. Renewable Energy Lab

Golden, CO 80401-3393

\author{
Brian E. Elbing \\ Applied Research Lab / Penn \\ State University \\ PO Box 30, State College, PA, \\ 16804-0030 \\ Michael Lawson \\ Nat. Renewable Energy Lab \\ 1617 Cole Blvd \\ Golden, CO 80401-3393 \\ Mirko Previsic \\ Re VisionConsulting, LLC \\ Sacramento, CA 95831 \\ mirko@re-vision.net
}

\begin{abstract}
Marine hydrokinetic devices are becoming a popular method for generating marine renewable energy worldwide. These devices generate electricity by converting the kinetic energy of moving water, wave motion or currents, into electrical energy through the use of a Power-Take-Off (PTO) system. Most PTO systems incorporate a mechanical or hydraulic drive train, power generator and electric control/conditioning system to deliver the generated electric power to the grid at the required state. Like wind turbine applications, the PTO system must be designed for high reliability, good efficiency, and long service life with reasonable maintenance requirements, low cost and an appropriate mechanical design for anticipated applied steady and unsteady loads. The ultimate goal of a PTO design is high efficiency, low maintenance and cost with a low impact on the device Cost-of-Energy (CoE).
\end{abstract}

\section{INTRODUCTION}

The long term success of hydrokinetic Marine Renewable devices will be strongly coupled to their ability to produce power in a competitive, cost-effective manner. A device's $\mathrm{CoE}$ is primarily associated with the device's overall efficiency, dependent on device design, and its manufacturing, deployment and maintenance costs. The total device efficiency includes contributions from (1) the energy extraction device design (rotor or wave energy absorber design) and (2) the PTO design including the coupling drive train (bearing, seals, gearbox, etc.) and the electric energy transmission system. The PTO design process should attempt to optimize PTO performance with consideration of overall device operation and impact on CoE. This design process should take into consideration device performance $(\mathrm{Cp}$, operating parameters and predicted steady and unsteady operating loads), the operating environment, overall PTO system efficiency and a trade-off study on system reliability, service life, maintenance schedule, weight and cost. In addition, the impact of unit scale-up from one device to many in an array installation can be integrated into the device CoE.

While the PTO design protocol and its components are similar to wind turbine PTO systems, the design process must additionally consider the marine environment requiring a more demanding design protocol. The PTO design for a marine turbine must consider increased system loads in water as opposed to air, a harsher operating environment (corrosion, water proofing or seals, marine fouling) and increased device deployment/accessibility costs. The presented PTO design protocol leverages design experience in marine vehicle system design and applies this to a $0.55 \mathrm{MW}$, horizontal axis hydrokinetic turbine device for tidal operation. The design process included a $\mathrm{CoE}$ assessment study identifying key aspects of the PTO design that impact CoE. 


\section{NOMENCLATURE}

$\mathrm{Cp} \quad$ Power coefficient $=\mathrm{P} /\left(0.5 \rho \mathrm{U}^{3}\right)$

PTO Power take off system

CoE Cost of energy

rpm revolutions per minute

MW mega Watt

$\mathrm{kW} \quad$ kilo Watt

$\mathrm{m} \quad$ meter

\section{DESIGN METHODOLOGY}

The PTO design process that will be described is in reference to a NREL $0.55 \mathrm{MW}$ hydrokinetic turbine designed under the US Dept. of Energy (DOE) Marine Renewable Energy Reference Model program. This reference model program focused on developing a device design with: (1) reasonable and validated power extraction performance, (2) a PTO system comprised of commercially available off-the shelf (COTS) components (if available) and (3) a design that can be manufactured and maintained with standard protocols. The goal of the design was to produce a device with reasonable performance specifications using common design process/tools with commercially available components that can be easily reproduced. The performance of the design would be validated through testing/demonstrations with the aim of assessing device design tools in general. Finally, a $\mathrm{CoE}$ analysis is performed to estimate the device overall $\mathrm{CoE}$ for a single unit implementation and the impact of multi-unit production and deployment on CoE.

The goal of the reference model project was to develop a simple robust design. So incorporating "radical turbine blade designs" would have created large uncertainty in the performance and $\mathrm{CoE}$ assessment, which is beyond the scope of the project. While the effort could have focused on an optimized device design to achieve high efficiency, such a design would probably incorporate radical turbine blade designs and unique PTO component designs specifically for operation in the marine environment. This design process would require an extensive system $R \& D$ design effort that would increase costs, raise the $\mathrm{CoE}$ and result in possibly poor reproducibility. An optimum turbine blade design may incorporate design features that could increase manufacturing costs substantially. Likewise, an optimized PTO design may have increased cost, weight and size that could adversely affect $\mathrm{CoE}$ through increased construction, deployment or maintenance costs, more than offsetting any long-term $\mathrm{CoE}$ reductions through performance gains. These features would not be characteristic of a reference model. One goal of the study was to utilize the $\mathrm{CoE}$ assessment to identify those aspects/components of the device design with the greatest impact on CoE.

The overall design process begins with close interactions between the device design engineers and system design engineers. The device specifications including power capacity, size and deployment location are first defined. A hydrodynamic design analysis is performed to define the rotor design (number of blades, diameter, etc.) and operating specifications (rpm, thrust, weight, anticipated steady and unsteady loads, etc.). For this study, NREL developed a two turbine system providing a combined 1.1 MW of power generation, see Lawson et al ${ }^{1}$. The turbine is designed to operate in the tidal resource of the Admiralty Inlet in Puget Sound, WA, USA. The dual turbine design is supported by a single tower anchored on the bed floor. A schematic of the overall system design is provided in Figure 1 with a summary of the pertinent physical and operational parameters. In addition, unsteady rotor loads due to inflow 
variations (turbulence, secondary flow components or time varying mass flow through the unit) ${ }^{2-4}$ or catastrophic events involving uneven shut down of one or both turbines was considered in this analysis. These unsteady loads can be large with frequency content that must be understood to avoid vibration excitation near the device or system natural frequency. Flow induced vibration on the rotor plane must be estimated as this will propagate through the drive train impacting PTO system and component performance (efficiency, maintenance and life cycle). Unsteady loading is a primary driver in PTO system failure (short term catastrophic or long
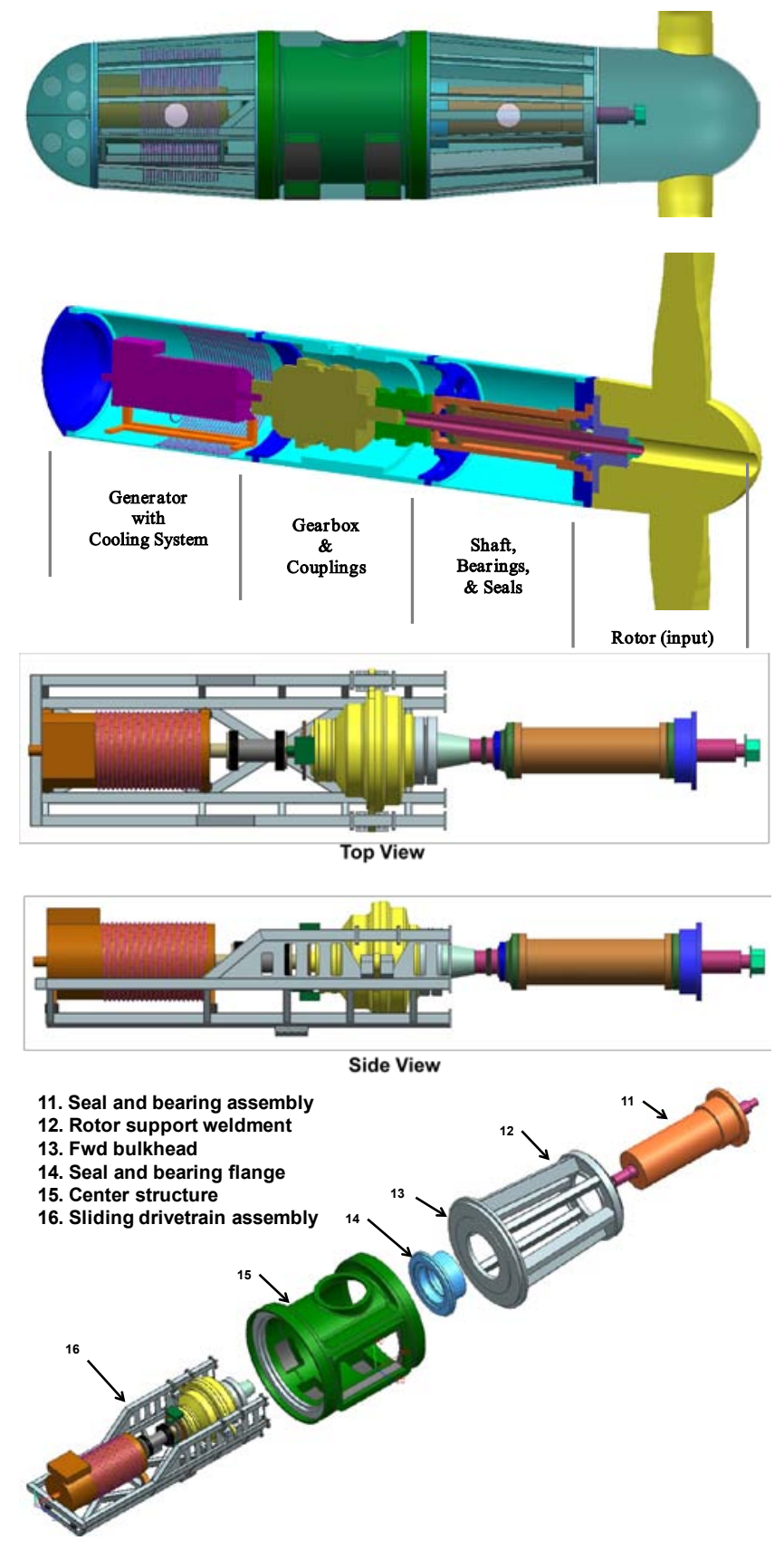

Figure 2. PTO drive assembly. term fatigue failure) in commercial wind turbine applications. A properly designed PTO system will take these unsteady loads into account and attempt to limit vibration propagation through the system.

The emphasis of the mechanical design of the PTO was to develop a robust design using commercially available components. This was done in an effort to preserve low overall system cost and retain system maintainability. All drive train components would be housed within a water tight nacelle to maintain overall system buoyancy and provide a closed seawater tight system to permit use of standard industrial or wind turbine components. The water tight nacelle design eliminates the need to seal each component individually in a water tight, seaworthy environment, provides easy access to the tower and cross-arms eliminating the need for water proof electrical connections and provides increased ballast volume for buoyancy control. Figure 2 is a design image of the proposed drive train assembly. The assembly consists of four major systems: the bearing and seal assembly, the gearbox and coupling section, generator section and the nacelle body. Each system will be discussed in more detail later in this manuscript. The power electronics for the two turbines would be located in the system tower.

\section{Drive Train Design}

The drive train design starts with the drive shaft specification. The current turbine design incorporates a variable blade pitch system for controlling turbine rpm. A hollow drive shaft design was sought to allow passage of power connectors for the electric blade pitch actuators. It is desirable to minimize drive shaft size while maintaining a performance specification with a factor of safety of at least 1.5 to reduce overall weight, and improve selection of supporting components such as seals, bearings and couplings.

The drive shaft specified for this design has a shaft size though the bearing bores of $317.5 \mathrm{~mm}$ with a $0.12 \mathrm{~m}$ bore through the center. The shaft material selected is 17-4 ph stainless steel. The material is specified to be at H1150 due to its greatly enhanced resistance to stress corrosion cracking when submersed in sea water. The factor of safety for the material in condition H1150 is 8.2 during normal operation and 2.5 taking into account the effect of the gusting moment. This design assumes that standard bearing locking nuts and hub attachment methods will be used.

The bearing and seal package was designed with the intent of protecting the balance of the drive train from sea water elements, supporting the turbine rotor and withstanding subsea gusting and unsteady loading which can propagate into the drive train from the rotor plane. The operational parameters, which the bearing and seal assembly would be subjected to, are tabulated in Figure 1. The drive train design needs to support the operational torque of the rotor and the system weight, the weight of the rotor plane and the weights of the directly connected couplings and components.

A modular bearing and seal package assembly was designed using commercially available standard components. 
Emphasis was placed on selecting components which would minimize maintenance and maximize bearing package component life. A modular bearing and seal package was proposed so that it could be assembled and tested separately from the balance of the assembly. Stock bearing and seal packages could be assembled and changed out as required thus minimizing turbine operational down time. The use of commercially available components, minimizing maintenance and maximizing component availability would reduce this contribution to the system CoE.

The resulting design concept, illustrated in Figure 3, incorporates the use of two Timken H961649/H961610 (317.5 $\mathrm{mm}$ bore) tapered roller bearings. The Timken bearings were selected due to their ability to sustain both radial and thrust loads. With the use of two of these bearings an additional thrust bearing is not required in the assembly. The bearings are grease lubricated and with the loads specified have a predicted L10 life of 16.5 years. Horsepower consumption for both bearings at the designated shaft speed is nominally 15 Watts. The design distance between the bearings is $1.83 \mathrm{~m}$. The distance between the centerline of the most outboard bearing and the center of gravity of the rotor assembly is $1.52 \mathrm{~m}$.

The main sea water seal in the assembly is a mechanical face seal (HSP-1014478-1, John Crane Inc.). The nominal shaft size in the seal sleeve mounting is $311 \mathrm{~mm}$. This seal, though more expensive that comparably sized lip seals, was selected due to its outstanding projected life of 20 years. This projected life cycle requires a two year maintenance interval for grease injection on the inboard side of the silicon carbide face seal to remove the minimal water seepage typical of this type of seal. The inboard grease seals (which do not touch sea water and are not subject to depth pressure) may be commercial lip seals. Energy consumption of the mechanical seal, due to friction, is

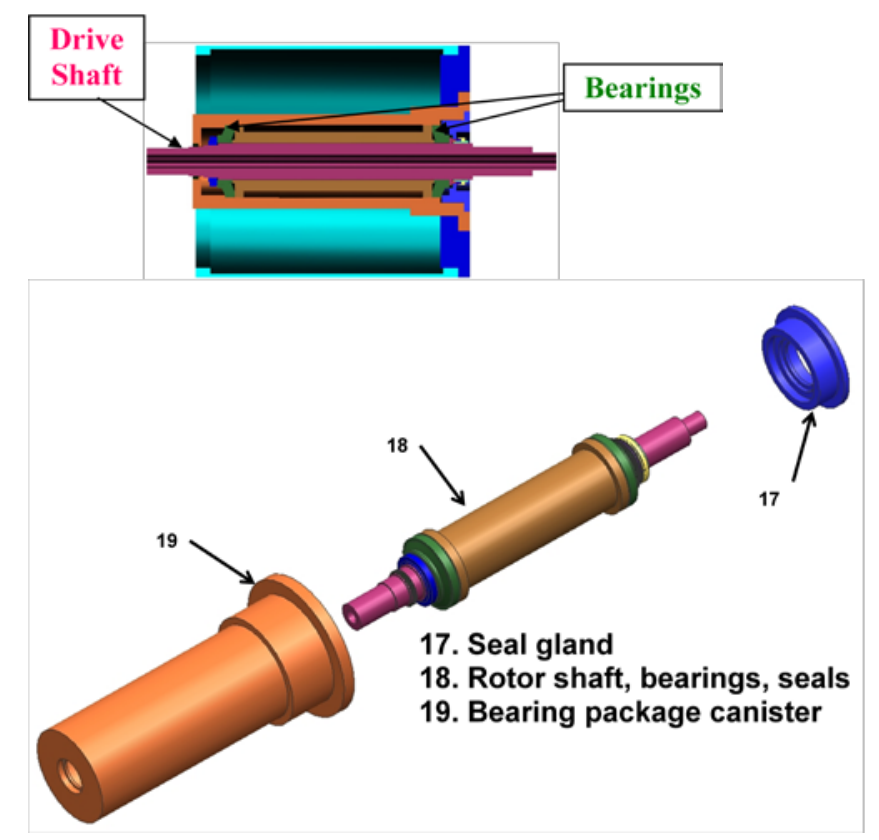

Figure 3 Bearing/seal package assembly. expected to be approximately 7 watts. The energy consumption of the grease seals is expected to be of the same order of magnitude.

\section{Gearbox and Couplings Design Overview}

The gearbox was specified as a commercial design from manufacturers of gearboxes for wind turbines and hydroturbines. The reference hydro-turbine had a rotor rpm of 10 to 12. The low rpm and high torque must be carefully considered in a gearbox selection. The gearbox is used to transmit torque from the rotor to a generator and is directly coupled to the drive train. Most commercial generators operate most efficiently at rotational speeds of hundreds of rpm. As a result, the gearbox, in this application, drives the generator as a speed increaser rather than a speed reducer. The gearbox contains sets of planetary gears and parallel shaft spur gears arranged in groups to develop the required gear ratio. A typical gearbox contains three sets of reduction gears. These gear sets can be arranged to have a common center for the input shaft and output shaft, or they can be arranged to have a horizontal offset of the output shaft from a centered input shaft. One advantage of the offset shafts is to have a pass-through for electrical cables or hydraulic lines used for blade pitch control from the generator side to the rotor side of the gearbox. This pass-through is located on the centerline of the drive train, in-line with the rotor shaft.

The gearbox transmits the torque through two connections to the drive train. On the low-speed turbine shaft side, a very robust coupling is used to transmit the full torque of the drive train, with some factor of safety for overload protection. On the high-speed generator side, a vibration dampening coupling is used. This coupling can also be designed with a torque-limiting feature to protect the generator. A mechanical disc brake with hydraulic actuators can be located on the high-speed gearbox side to provide controlled braking and to protect the drive transmission components. Life

Gearbox Specifications and Designs: Extended Service

The gearboxes that were considered for this study had specific component design features. The planetary gears were mounted on shafts with tapered roller bearings in an arrangement called an "Integrated Flex-pin Bearing (IFB)" . This technology was developed to minimize the angular misalignment in the planet gears during transient torsional overloads from the rotor. It also improved the life of the planetary gears and permitted the gears and mounting arrangements to be made smaller and lighter. , The gearbox design included an auxiliary output shaft to drive one or more hydraulic pumps. The hydraulic pumps were used for oil lubrication for the gearbox. The auxiliary hydraulic power was also used for blade pitch adjustments and for operating the calipers for the disc brake. The gearbox lubrication systems were chosen for longevity and needed for remote monitoring. The systems included redundant oil filters and particulate sensors to switch over to a new filter automatically as needed. Multiple sensors were built into the gearboxes to sense vibration levels, temperature and oil supply pressure for proper 
lubrication. Oil cooling and conditioning were designed into the lubrication system, with redundant components. Gearbox components, model and manufacturer, are provided in the maintenance and life cycle section of the paper.

The gearbox was specified with a closed-loop cooling system that consisted of circulating lubrication oil through a heat exchanger ${ }^{6}$. The heat exchanger consisted of a shell and tube design that was located in a pumping system tied into the generator cooling system, but in a separate loop. The heat exchanger consisted of a series of cylindrical coils inside the nacelle wall in a separate system from the generator cooling coils. Gearbox lubricating oil is pumped through the shell and tube heat exchanger for cooling. The gearbox cooling system consisted of a closed-loop pumping system with redundant pumps and controls. The controls consisted of temperature regulators and sensors to maintain the gearbox at the correct operating temperature. The gearbox cooling system was totally enclosed inside of the nacelle and was not subject to corrosion from the surrounding seawater. For a cold startup, a gearbox lubrication oil heating system was used that bypassed the cooling system with a set of control valves and temperature sensors.

Coupling Specifications and Designs: Extended Service Life

The couplings that were considered for this study included some design features that were required for long service life and overload protection. The main rotor shaft is hollow to minimize weight and to provide a pass-through of electrical cables or hydraulic lines. The input coupling to the gearbox would be an integrated style "shrink disc" coupling or a flexible coupling, depending on the ability to align the rotor shaft and the gearbox input shaft. The shrink disc coupling fits onto the input shaft of the gearbox requiring precise alignment during assembly of the rotor shaft. The assembly also requires special tools to properly torque the studs on the coupling to generate the clamping forces required. The flexible couplings that were considered in the design incorporate a set of crowned gear splines for both angular as well as offset misalignment. The gear lubricant and seals were specified for long service life, especially with the low speed of the rotor shaft and the marine operating environment. The resilient couplings that were considered for the generator or high-speed side of the gearbox drive were designed for vibration control to protect the generator. An additional feature was a "Multislip Torque Limiter" ${ }^{7}$ (2) that would provide torque limit to protect the generator drive. The mechanical vibration control components also act as electrical insulators to protect the drive from electrical leakage current and electrical corrosion. An additional feature of the resilient coupling components is the reduction of the transmission of structure-borne noise in the drive.

\section{Generator}

The power conversion system greatly impacts the entire design of the power train delivery system, and the choice of using either an induction generator or a permanent magnet (PM) generator could lead to two very distinct designs. While induction generators are widely used and well understood, for the current MHK device a PM generator was selected. As pointed out by Melfi et al. ${ }^{8}$, the PM generators are appealing because they are efficient, reliable, and have improved performance (i.e. high power density, low power factor, low rotor temperature) and flexibility (i.e. synchronous operation). The increased flexibility makes the operation frequency a degree of freedom in the system, which allows for operation at base frequencies other than 50 or $60 \mathrm{~Hz}$. However, there is a price associated with this freedom, since the output frequency must be 50 or $60 \mathrm{~Hz}$ an inverter must be added to the system. It was decided that the advantages of the PM generator outweighed the increase in complexity of the electric conditioning system. The model selected was the ABB model AMZ500LE10. Similarly, the remaining power conversion components (transformer, drive control, cables, and connectors) were primarily selected based on available information and were treated as off-the-shelf estimates for this conceptual design. Generator and electric conditioning components, model and manufacturer, are provided in the maintenance and life cycle section of the paper.

The synchronous induction generator ${ }^{9}$ was designed with an integral cooling jacket. The generator design included a cylindrical outer housing that contained a series of serpentine channels where cooling fluid was pumped through the cooling jacket. A heat exchanger in the form of a series of cylindrical coils was located inside of the aft nacelle support housing along the inner surface of the steel shell. Cooling fluid was pumped from the cooling jacket of the generator to the cylindrical coils to facilitate the heat transfer to the surrounding seawater through the steel wall of the aft nacelle support housing. The generator cooling system consisted of a closed-loop pumping system with redundant pumps and controls. The controls consisted of temperature regulators and sensors to maintain the generator at the correct operating temperature. The generator cooling system was totally enclosed inside of the nacelle and was not subject to corrosion from the surrounding seawater.

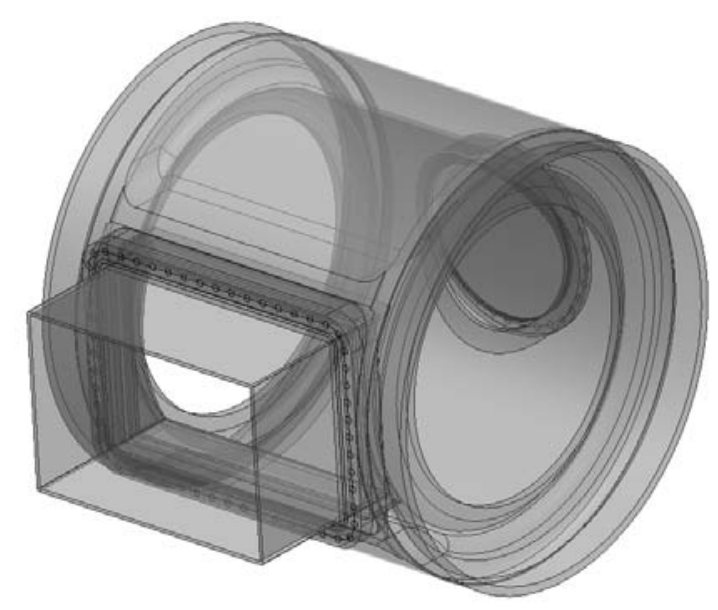

Figure 4. Center support housing 


\section{Nacelle and Support Structure}

The support structure for the turbine was designed to house the drive components and to act as the means of connection to the support arms on either side of the main support pile. The center support housing of each nacelle acts as this support structure and is also designed to provide access to the gearbox, shown in Figure 4. The center support housing was designed with cylindrical end flanges to mate with the forward and aft nacelle conical support sections. Rectangular side flanges were designed to mate with the rectangular support arms. The center support housing could be made from cast steel or fabricated from steel as a weldment. The outer contour of the center support housing was made from thin rolled steel plate and could be attached to the center housing in split sections. Access ports were located opposite the rectangular side flanges and at other locations to provide access for inspection and maintenance. Bulkheads were designed to be located at the forward and aft ends to mount the gearbox and to provide support for the drive components.

The forward conical support housing was designed to support the rotor and drive shaft with the bearing and seal housing, shown in Figure 5. It consisted of an aft cylindrical bulkhead flange that mated with the forward end of the center support housing and a forward bulkhead flange that mated with the forward end of the bearing and seal housing near the rotor hub. Steel box beams were designed to tie the forward and aft steel bulkhead flanges together into an integrated welded support structure. The outer skin consisted of rolled steel plates with rolled "T-section" rings welded to the inside to provide a water-tight pressure hull. This unified structure transferred the rotor forces (bending, axial and torsional) from the forward conical support housing to the center support housing. The design combined strength and rigidity with low weight. The design will require further refinement with FEA analysis to optimize the structural components.

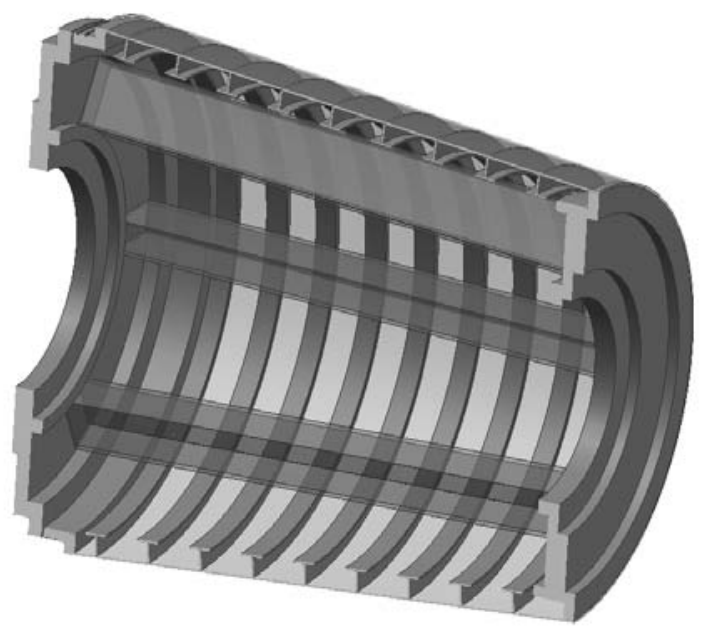

Figure 5. Forward conical support housing.
The aft conical support housing was designed to enclose the generator in a water-tight enclosure and to provide access on the aft end, shown in Figure 3. It consisted of a forward cylindrical flange that mated with the aft end of the center support housing and an aft flange that mated with the access port on the aft end. The outer skin consisted of rolled steel plates with rolled "T-section" rings welded to the inside to provide a water-tight pressure hull. The aft access port consisted of a hemispherical shell with rolled "T-section" rings welded to the inside for support. The design combined strength and rigidity with low weight. The design was in the preliminary stages and will require further refinement with FEA analysis to optimize the structural components. The assembled support structures are shown in Figures 7 and 8.

The nacelle was designed for easy system assembly and access for maintenance. Access ports are provided in critical locations to enable necessary maintenance activities in an efficient manner. System build up is performed in center housing out fashion starting with the center conical support housing and working outward aft and forward. The generator/ gearbox assembly is mounted to a sliding rail system permitting easy access to these components through removal of the aft conical section. Figure 2 illustrates a blow-out of this design.

\section{Maintenance and Life Cycle}

The life cycle and preventative maintenance for large PTO system components can be comprehensive and can affect the overall $\mathrm{CoE}$ for a marine hydrokinetic turbine. To estimate an accurate $\mathrm{CoE}$ for the device, the maintenance and projected replacement requirements for the main PTO components were estimated based on manufacturer specifications /recommendations and design/operation experience with similar components used in the marine environment. The following are a statement of the data collected for each component. Information for the nacelle body was not available though a major concern in a marine water environment would be bio fouling.

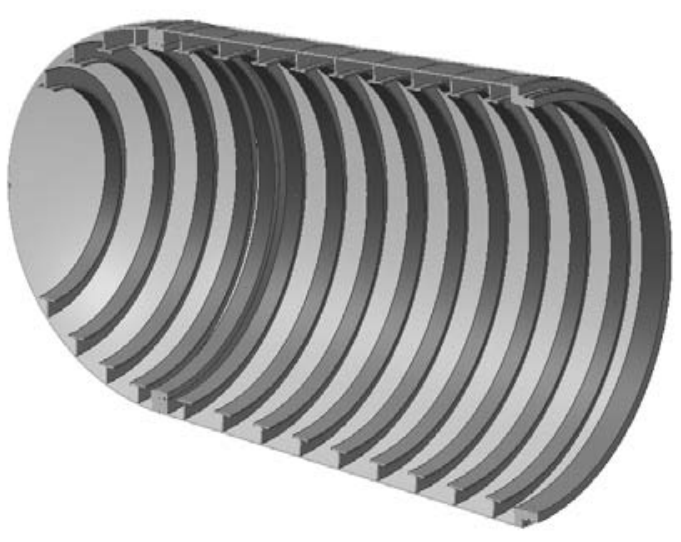

Figure 6. Aft conical support housing. 


\section{Mechanical face sea water seal}

John Crane Seal provided by Hoffman Kane Distributors Pittsburgh PA. Part \# HSP-1014478-1.

Preventative: replace $\mathrm{O}$ rings, springs \& primary carbon ring and lap carbide mating ring every 2 years,

Component life: 20 or more years if used in clean water, 10 years of used in brown water.

2. Shaft Isolation Coupling - Gearbox to Generator

Renold Hi-Tec (direct from factory), Renold RB-3.86 $\$ 4769$ net each (FOB Westfield, New York), est. finished weight is $97 \mathrm{lb}$. No lubrication required, rubber elements Estimated life of rubber elements - indefinite

\section{Drive Shaft Bearings (2)}

The Timken Company Canton Ohio, Part \# H961649H961610

Preventative Maintenance: annual inspection, lubrication to be provided via automated grease or oil lube system.

Component Life: Using a Timken on line program assuming that the bearings are operated continuously a life of 16.5 years is predicted.

NOTE: The life result is based on a report from the Timken Tech Center date January 24, 2011;

Preliminary based on overhung load of "DRY" rotor weight; pending a more detailed design \& system analysis .

4. In board dry oil /grease seal (1)

SKF: V-ring Seal provided by Hoffman Kane Distributors Pittsburgh PA. Part \# TBD, Price \$974.

Component Life: Approximate life 2 years based on user experience.

\section{Rotor Drive Shaft (1)}

Preventative Maintenance: annual inspection, possible resurfacing in wear areas.

Component Life: Designed for stresses to be under the endurance limit of the material during normal operation. Design factor of safety in gust conditions is 2.5. Minimum design factor of safety during normal operation is 8 . These factors of safety are based on overhung load of "DRY" rotor weight; pending a more detailed design \& system analysis including effects of dynamic loading. It should be noted the that the drive train has been designed such that the shaft and bearings assume all radial loads generated at the rotor plane in addition to torque and thrust. The gearbox is subject to no extraneous rotor loads other than torque. The housing containing this shaft, the bearings and the associated seals is in one self-contained assembly. This assembly can be removed as a completed assembly for ease of replacement and efficient maintenance with minimal down time. A spare assembly could be maintained such that the entire bearing and seal package could be removed, inspected and any necessary items replaced or repaired with periodic maintenance cycles. With the current preliminary bearing selection having an estimated life of 16.5 years, this bearing \& seal package exchange could be done every 2 to 4 years.

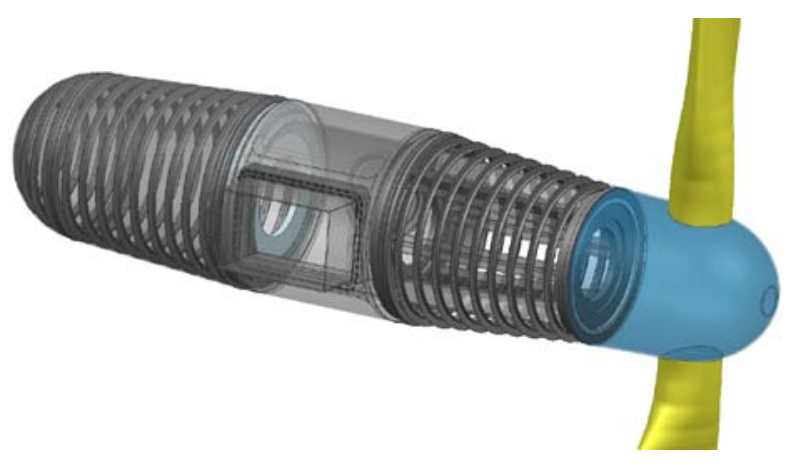

Figure 7. Assembled support structures.

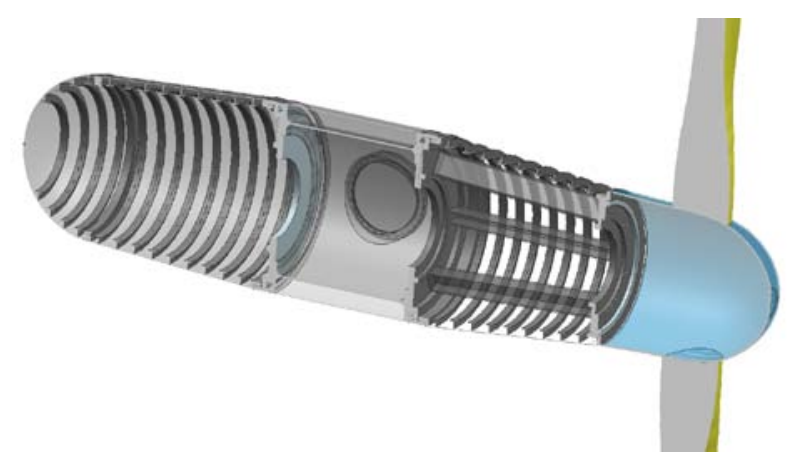

Figure 8. Section through Assembled Support Structures.

\section{Generator}

Manufacturer: ABB, Model: AMZ500LE10.

Preventive maintenance: Slip ring unit check every year/other maintain 5-10 year interval.

Lifecycle: over 10 to 20 years if properly maintained.

\section{Transformer}

Manufacturer: ABB, Type: 500 kVA Liquid Filled Pad mounted Transformer Green-R-Pad FS or EFS.

Preventive maintenance: gauge readings, tank leaks, control wiring \& circuits, liquid dielectric test, temperature scan, insulator cleanliness need to be check once a year.

Lifecycle: with proper maintenance typically greater than 20 years.

\section{Drive Control}

Manufacturer: ABB, Model: ACS800-17-0790-7.

Preventive maintenance: Heat sink temperature check \& cleaning $=6$ to 12 months $/$ change cooling fan every 6 years/capacitor change every 10 years.

Component life: Fan life $\sim 50,000$ operating hours/capacitor lifespan $=45,000$ ( $\sim 5$ years $)$ to 90,000 hours.

\section{Cost \& Economic Assessment of the PTO}

The lifecycle-cost analysis for the drive train was performed by RE Vision Consulting. In order to understand the lifecycle cost of the powertrain, the following areas need to be understood: (1) Manufacturing cost at commercial production levels, (2) regular maintenance requirements (i.e. oil change), and (3) failure rates. Single unit pricing, while a useful 
indicator for pilot cost, is a poor indicator for commercial scale production runs. In order to provide an understanding of the commercial system cost, an analogous cost assessment was carried out to estimate the lifecycle cost from these systems using wind-turbine cost data.

An important difference between a tidal turbine and a wind turbine is the ease of access to the powertrain, which drives the intervention requirements. Because maintenance access at sea is extremely expensive, reducing the failure and maintenance cycles is a key consideration in the design of these systems. Redundancies were introduced in the design to reduce the intervention interval to a minimum (1.1 annual repairs for a 2 rotor water turbine vs. 3.7 for a single rotor wind turbine with a comparable power rating). While this measure increased the total capital cost of the system by almost $20 \%$, it reduces overall lifecycle cost of the system by reducing the number of times the device has to be recovered over its lifetime.

To characterize the cost of these intervention procedures, a conceptual design for a dedicated vessel was established that would allow the deployment and recovery of the powertrain assembly. After reviewing handling requirements and the potential of meeting those with vessels of opportunity, it was determined that the most cost-effective approach would be to have a custom designed vessel form an integral part of the plant and staff it with a permanent crew. This is similar to the approach taken by many leading tidal device manufacturers that are realizing that the intervention requirement frequency and the uniqueness of the environment in a tidal race would be best addressed by use of specialty vessel that is equipped to meet the requirements of the task. Total vessel cost was estimated at $\$ 13$ million to $\$ 16$ million. A crew of 20 men would be required to safely operate the vessel in a tidal race. Other cost elements include (1) insurance, (2) replacement part cost, and (3) repair personnel cost, (4) facilities and infrastructure.

With the exception of the sea water bearing and seal assembly and the supporting structure for the PTO, the balance of the drive train uses existing wind turbine technology. To estimate the cost of a commercially mature production level, results from NREL's WindPACT study were used and modified to take into account the following design differences between wind and water turbine designs:

1. Lower rotor shaft rpm resulting in increased gearbox cost

2. Difference in rotor designs

3. Design redundancies in the drive train to minimize the number of annual repairs for the water turbine

4. Sealing requirements

The following figure shows the relative cost comparison between a wind-power drive-train, an equivalent tidal turbine drive-train and the redundant tidal-turbine drive-train.
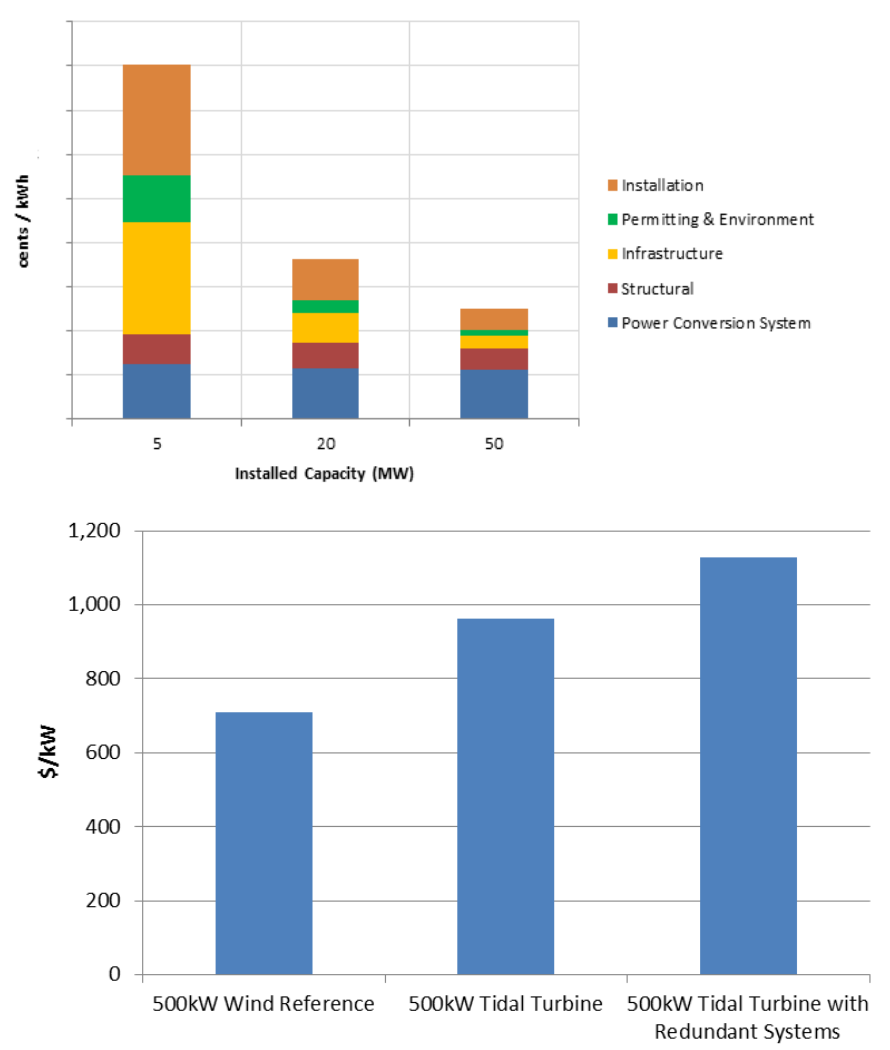

Figure 9: Capital cost of different drive-train configurations

It is important to understand that the design of a powertrain cannot be carried out in isolation from the system design. Lifecycle cost data from all systems were used to establish a comprehensive lifecycle cost model. The resulting data was subsequently used to optimize the intervention intervals for the powertrain. While actual cost of electricity data for this project has not been released yet, the following illustration shows the contribution of individual cost centers to the total system cost (O\&M costs are not shown in this figure). It shows that the powertrain's contribution to total cost will likely be significant at commercial scale.

\section{Acknowledgments}

The authors would like to acknowledge the support of the US Dept. of Energy and Michael Reed, Program Manager, for support of this research design effort. DOE Research contracts \#775396.

\section{REFERENCES}

1 Lawson, M.J., Li, Y., and Sale, D.C., 'Development and Verification of a Computational Fluid Dynamics Model of a horizontal-Axis Tidal Current Turbine,' OMAE2011-49863, June 19024, 2011, Rotterdam, The Netherlands.

2 Leishmann, J.G., 'Challenges in Modeling the Unsteady Aerodynamics of Wind Turbines', AIAA Paper 2002-0037, 
$21^{\text {st }}$ ASME Wind Energy Symposium and the $40^{\text {th }}$ AIAA Aerospace Sciences Meeting, Reno, NV, January 14-17, 2002

3 Leishmann, J.G., Principles of Helicopter Aerodynamics, $2^{\text {nd }}$ Edition, NY, Cambridge University Press, 2006.

4 Koncoski, J.J., Paterson, E.G., Zierke, W.C., 'A BladeElement Model of Propeller Unsteady Forces for Computational Fluid Dynamics Simulations," Developments in Marine CFD, The Royal Institute of Naval Architects, London, UK, March 22-23, 2011.

5 Machine Design Magazine, Flexible Gears Bolster WindTurbine Reliability, Kenneth J. Korane, August 9, 2007; Wind Energy Solutions, The Timken Company, Canton, $\mathrm{OH}$
6 Innovative Gearboxes for Wind Turbines, Rexroth Bosch Group.

7 CENTA Wind Power, CENTA Power Transmission Products, CENTA Corp., Aurora, IL

8 Melfi, M., Evon, S. \& McElveen, R. (2009) "Induction versus permanent magnet motors," Industry Applications Magazine, IEEE, 15(6), 28-35

9 Wind Turbine Generators - Reliable Technology for all Turbine Applications, ABB Corp., Motors/Generators Division. 